\title{
Menstruation and Religion: Developing a Critical Menstrual Studies Approach
}

\author{
Ilana Coben
}

\section{INTRODUCTION}

In September 2018, the Supreme Court of India overruled a ban preventing women and girls of menstruating age (between ten and 50) from entering the Sabarimala Temple in Kerala, India (Indian Young Lawyers Association \& Ors. v. The State of Kerala \& Ors, S.C.C. I [2018]). The ruling came three years after \#happytobleed, a viral social media campaign, drew international outcry to a 2015 Sabarimala Temple board statement. The board stated that one day women between ten and 50, traditionally prohibited from entering the temple lest they distract the deity (perceived to be a celibate bachelor), may be able to enter the temple if they are not actually menstruating (BBC 2015). Nikita Azad, founder of the campaign, spoke out against the implied impurity of menstruation, and the campaign quickly became "an initiative against sexism" and perceived misogyny (Azad 2015). While the Supreme Court's ruling that it is illegal to prevent any woman from entering Sabarimala was welcomed by countless individuals and Kerala's state government, the ruling also set off "an uproar that has become a months-long battle over differences of caste, gender, party politics, and history" (Nair 2019). Indeed, the controversy exemplifies how the intersection of menstruation and religion engages not only contested classifications of the impure and the pure but urgent issues related to gender equality, hierarchies, delineations of communities, and boundaries of power as well.

This complex intersection is well-documented in an extensive body of literature exploring menstruation and religion from many disciplinary perspectives. While there is not space here to chronicle every way menstruation and religion have become topics of scholarship, activism, and reflection, this chapter discusses the possibilities and limitations of how the relationship 
between menstruation and religion is imagined and studied. Studies of menstruation and religion often concentrate on ritual impurity and associated prescriptive prohibitions to the extent that 'menstruation-and-religion' comes to connote a religion's classification of menstruation and instructions for what a menstruant should and should not do (see Bhartiya 2013; Dunnavant and Roberts 2012). Such references remove menstruation and menstrual practices from larger contextual frameworks which more targeted religion-specific scholarship may engage. They also tend to follow an established pattern of analysis-"the paradox approach" (Avishai 2008, 410)-which seeks to resolve the 'mystery' of compliance with what are perceived to be negative and restrictive traditions.

While existing scholarship also critiques and adapts "the paradox approach" to explore how women find meaning in and exert agency through observance of menstrual practices (Avishai 2008; Sharma 2014), this chapter offers an alternative approach. The chapter addresses the abstraction of religiously motivated menstrual practices from their wider contexts in order to more effectively engage with them and expand the discourse of menstruation and religion beyond a framework of negative restrictions. Recognizing these contextual larger systems demystifies menstrual practices and allows the discourse to include under-discussed themes such as the relationship between menstrual practices and the establishment and maintenance of personal and communal identities and hierarchies, gendered roles and expectations within religions, and how religiously motivated menstrual practices serve to channel women's sexuality.

In discussing these themes, I advance the menstruation and religion conversation beyond menstruation and a specific religion such as Hinduism, Christianity, or Judaism to religion as a cultural institution in which menstruation plays a practical and theoretical role. The relationships between menstruation and religion, and religion and culture suggest that menstruation is a cultural phenomenon just as much as it is a physiological one. Religiously and culturally motivated practices compel certain behaviors of menstruants, and those practices, and what menstruation symbolizes and communicates within a particular system, ultimately (re)produce religion and culture themselves (see Maharaj and Winkler [Chapter 15] in this volume).

To explore the ways in which menstruation is 'religion-producing,' I review literature on menstruation in Judaism and Hinduism, putting key ideas in conversation with each other. Both Judaism and Hinduism have defined menstrual traditions and prescriptions, often discussed within the framework of impurity and pollution. This framework, though worthy of attention, must be appropriately contextualized to avoid incorrectly implying that in each religious context menstruation is only a source of pollution on the one hand, and that menstruation is the only source of impurity and pollution on the other. The scholarship discussed here cannot provide comprehensive accounts of all perspectives on menstruation in Judaism and Hinduism. However, engaging examples from two capacious religious traditions offers both detailed accounts of specific practices and discussion of larger themes at play. 
In the first section, I address the impurity framework and menstrual restriction discourse that dominates the discussion of menstruation and religion. In this first section, I show how in both Judaism and Hinduism menstruation is embedded within larger purity systems and codes of behavior which offer deeper understandings of the restriction discourse overall. With this understanding established, I show that the restriction discourse does not fully represent menstruation and religion through a discussion of how menstruation and menstrual practices can be associated with auspiciousness and positive, unique power. In the second section, I widen the scope of engagement and discuss how menstruation and religiously motivated menstrual practices can be read as defining factors and safeguards of the boundaries of specific religious communities in both traditions. Relevant scholarship shows the role menstruation plays in identity formation and explores the extent to which the onus of maintaining religious boundaries falls on women, channeled through their reproductive capabilities and sexualities. Finally, I discuss how menstruation and menstrual practices have become vehicles for wider religious transformation and activism and suggest arenas for further exploration.

\section{The Impurity Framework and Restrictions Discourse: Possibilities AND Limitations}

In both Judaism and Hinduism, menstruation is classified as a time of impurity according to systems that govern bodily fluids and interactions between individuals. It is important to study the context these systems create in addition to the top-level impurity classification. When removed from a specific religious context, the 'impurity' concept and its associated prescriptions often become framed as 'traditional practices,' 'myths, and 'religious superstitions' that seem to apply only to menstruation. Further, contextualizing menstrual practices offers more opportunity for discussion than the classification of impurity does alone, as demonstrated in the second part of this chapter.

\section{Contexts for Menstruation in Judaism}

In Judaism, menstruation and a menstruating woman fall under the Hebrew term Niddah, which is derived from the word meaning "separation" (Meacham 2009). Chapter 15 of Leviticus, a book in the Hebrew Bible, addresses menstruation within an instructional system concerned with impurity which, in the biblical context, "renders a person unfit to approach the altar" and engage in Temple-related rituals (Collins 2004, 145). There are three sources of impurity within this system: encountering a corpse, specific bodily emissions, and skin diseases (Collins 2004, 147). In the biblical context, bodily emissions include: menstruation, non-menstrual vaginal discharges, lochial bleeding, and seminal or non-seminal discharges 
(Meacham 2009, "Leviticus 15"). While the biblical purity system treats men's and women's bodily emissions and resulting impurity similarly, there are differences regarding communicability and length of impurity between them (Hauptman 1998, 169). Menstrual bleeding, non-menstrual uterine bleeding, and non-seminal discharges all cause communicable impurity (understood to be transferred through physical contact or contact with something someone experiencing impurity has touched) while seminal discharge does not. The length of impurity for menstruation lasts for seven days but only one day for seminal discharge. As part of a larger list of prohibited sexual behaviors and partners, men are instructed to avoid a menstruating woman (Leviticus 18:19) in order to prevent sexual relations, which would transmit seven days of impurity, an undesired state that would limit ritual engagement, to the sexual partner (Meacham 2009, "Leviticus 15").

Extensive scholarship explores why specific bodily emissions cause impurity in the biblical context (see Whitekettle 1996; Boyarin 1993). For example, Howard Eilberg-Schwartz (1990) suggests that the system can be read as demarcating life and death. Certain fluids, like menstruation and semen, read as missed opportunities for conception, become symbolic of death and render impurity through connoting the impurity of death. Alternatively, impurity can be read as related to uncontrollability; the less controllable a bodily fluid, the more polluting. Menstrual blood and non-seminal discharge, released passively, render impurity for seven days while tears, sweat, and mucus, understood as more controllable, do not (Eilberg-Schwartz $1990,182)$. In the biblical context, childbirth also results in impurity leading some to suggest that the key commonality among the three categories of impurity is liminality, or "the edges of life" (Collins 2004, 147). While many interpretations exist, some feminist readings suggest that the biblical purity system itself can be read as one that "privileges normal males and disadvantages all females and males with abnormal discharge" (Meacham 2009, "Leviticus 15").

The end of the biblical period and the destruction of the Second Temple in 70 C.E. rendered the purity system largely inapplicable, and the rabbinic period which followed saw changes in the practical significance of the purity system (Meacham 1999, 29). ${ }^{1}$ During this period, sages expounded upon the contents of the Hebrew Bible through recorded discussions that comprise the Talmud, the codified body of Jewish law. While prescriptions for non-seminal emissions and various skin conditions lost their practical importance, prescriptions concerning menstruation remained. In fact, Talmudic discourse resulted in the addition of stringencies to the foundational guidelines regarding menstruation laid out in Leviticus 15 (Hauptman 1998, 169). These changes are recorded in discussions in Tractate Niddah, a book of the Talmud. These discussions produced the practices, referred to as the Laws of Niddah, observed by many Jewish individuals today. The Laws of Niddah prohibit contact between a married couple during the days of a woman's period and for seven 'clean' days following the cessation of bleeding until she 
immerses in a miqvah (ritual bath) for purification (Avishai 2008, 414; see also Mirvis [Chapter 12] as well as Maharaj and Winkler [Chapter 15] in this volume). Physical contact during menstruation is prohibited to avoid sexual arousal and intercourse which would communicate impurity to the man (Hauptman 1998, 161). Proper adherence is motivated in part because a child conceived during menstruation or before proper purification is categorized as "severely defiled" (Avishai 2008, 414). In fact, some scholars argue that the rabbinic concern in the Talmud is not so much with restrictions for menstruating individuals, but rather the conditions under which they become permissible to have sex with. Although the text is 'about' menstruation and women's bodies, it can be interpreted as a text focused more on the concerns of men (Hauptman 1998, 169), a point this chapter addresses in more detail later.

In summary, in Judaism, menstruation was once part of a larger system that governed many types of bodily emissions; over time and through rabbinic discussion, prescriptions regarding menstruation were adapted to remain relevant and observable, in part because the status of future generations depended upon their proper observance. The Laws of Niddah are observed in Orthodox Jewish communities where they are considered part of Halacha (binding divinely inspired Jewish law), and are "identified as the backbone of Jewish family life and as a mainstay of Jewish community" (Steinberg 1997, 11). Since most liberal Jewish denominations do not consider Halacha to be binding in the same way Orthodox denominations do, and since some may take issue with a function of the body being rendered impure (Meacham 1999, 33), they have rejected compulsory observance of the Laws of Niddah turning them into a personal choice.

\section{Contexts for Menstruation in Hinduism: Brabmanical and Non-Brabmanical Approaches}

Although recognized as a singular world religion, Hinduism "encompasses a broad array of traditions, sects, and religious-philosophical schools" (Apffel-Marglin 2008, 54). Each subset offers a distinct conceptualization of menstruation, but adequately discussing all traditions, sects, and religious-philosophical schools associated with Hinduism is well beyond the scope of this chapter. Because Brahmanical Hinduism (the dominant and subsuming form of Hinduism propelled by the priestly [Brahmin] caste) largely shapes prevailing attitudes toward menstruation (Hembroff 2010,30), it is useful to understand the purity system inherent to it. Non-Brahmanical philosophies and framings, a selection of which this section also addresses, provide alternative explanations and expand the Brahmanical purity framework to explore how menstrual restrictions can be linked to auspiciousness and positivity. ${ }^{2}$

Dharma literature (religious law or sacred norms) provides Brahmanical codes of conduct for Hindu society. Manu Smriti (c. 100 CE) is considered the most definitive, authoritative work of Dharma literature (Olivelle 2004, 3) and offers 
"the most systematic of Brahmana ideologies" (Chakravarti 2003, 71). The text provides detailed guidance on everything from food preparation and hygiene routines to ritual observance and religious study. Primarily addressed toward Brahmin men, the text outlines proper behaviors for them vis-a-vis women and members of other castes and illustrates an 'ideal' society strictly ordered on personal and communal levels. Manu Smriti's treatment of menstruation is considered emblematic of the normative discourse around menstruation in Hinduism (Leslie 1994, 72) which must be understood within the larger systems of the text.

Interwoven within Manu Smriti are direct and indirect instructions for women and men from different castes of the four-tiered system and for those who fall outside the caste system (considered 'untouchable' according to the text, often referred to as Dalit). Some scholars even suggest that Manu Smriti's overarching intention is to maintain the boundaries of the text's idealized society and to preserve the purity of Brahmin men, reflecting the concerns of the Brahmin authors (Doniger 1991, xxiii). As this section demonstrates, the system that guides Brahmin men's behaviors regarding menstruating women overlaps with the system that governs interactions with 'low-caste' and Dalit individuals (see Sukumar [Chapter 13] in this volume).

Manu Smriti outlines 12 impurities of the body, including "oily exudations, semen, blood, (the fatty substance of the) brain, urine, feces, mucus, ear-wax, phlegm, tears, the rheum of the eyes, and sweat" (Sacred Texts, n.d., 5.135). Men and women are instructed to purify themselves of these substances according to their caste, and coming into contact with any impure entity, whether a substance or a person who is impure, can communicate temporary impurity (Ibid., 5.143). Indeed, the communicability of pollution and impurity through touch, sex, and the sharing of food is a key theme of the text.

In Manu Smriti, menstruating women are included within lists of individuals to be avoided and are likened to 'low-caste' individuals. Brahmin men are instructed to avoid sharing a bed with and to avoid having sex with a woman who is menstruating, no matter how much he might desire to (Ibid., 4.40); to avoid eating food that has been touched by a menstruating woman (Ibid., 4.208); and to avoid holding a conversation with a menstruating woman (Ibid., 4.57). According to Manu Smriti, shunning a woman when she menstruates increases a man's wisdom and long life (Ibid., 4.42). It is also noted that a 'high-caste' man should not touch food that belongs to 'lower caste' people, that has been touched by animals, or that has hair or bugs in it. The two strands of instructions are unified when Manu Smriti states that if a man touches an "untouchable," "a menstruating woman," "anyone who has fallen (from his caste)," "a woman who has just given birth," "a corpse," or anyone who has touched a corpse, he requires cleansing through a bath (Ibid., 5.85). The text suggests that menstruation is one of many substances and socially constructed hierarchies perceived to communicate impurity and to threaten the status of Brahmin men. 
In addition to placing menstruation within the system governing bodily purity and caste distinction, Manu Smriti draws on an idea that menstruation is a sign of women's inherent impurity (Leslie 1994, 66), an idea established in a Vedic story that predates the Dharma text which links together menstruation, guilt, sexuality, and Brahmanicide. In this story, the god Indra commits Brahmanicide by killing Vicvarupa, a demon-like Brahmin. In order to absolve himself of this "sin," Indra appeals to the earth, trees, and women to each take a third of his guilt; they each do and receive a boon (blessing) in exchange. After the women take on Indra's guilt, "it [the guilt] became (a woman) with stained garments; therefore, one should not converse with (a woman) with stained garments, one should not sit with her, nor eat her food, for she keeps emitting the colour of guilt" (Keith 1914 [2-5-1]). In this story, menstruation is established as a sign of the worst sin in Brahmanical Hindu ideology. ${ }^{3}$ Practices such as not entering the kitchen, not cooking for or touching others, avoiding sex, and refraining from entering temples during menstruation (Bhartiya 2013,524), which fit within the instructions governing control of bodily substances and caste distinction recounted in Manu Smriti, are intensified by the Vedic story associating moral negativity with menstruation. These two approaches overlap in the Vedic story itself when the text explains that the progeny of a woman who has intercourse during menstruation will be "accursed" and that a man should therefore not have intercourse with a menstruating woman. A later Dharma text addressing the specific duties of a Brahmin wife emphasizes this idea, asserting that a child resulting from intercourse during menstruation will be an "untouchable" or "cursed" (Leslie 1989, 285). In summary, menstruation is associated with impurity in Brahmanical Hinduism due to its position within codified systems governing bodily secretions and caste distinction, as well as its association with sin and guilt.

While these Brahmanical approaches to menstruation may be considered normative, other schools point to menstrual restrictions as indicative of menstruation's auspicious and powerful nature, demonstrating the diversity of approaches to menstruation beyond of framework of restrictions even within what is perceived as a singular religion. Sangam literature (100-500 CE) offers one such example. Sangam literature represents a Dravidian worldview (as opposed to a Sanskrit-Aryan worldview) which was a precursor to the Brahmanical system that eventually became the religion associated with power throughout the subcontinent (Jenett 2005, 176). Originating from the geographic region now known as Tamil Nadu and Kerala in south India, Sangam poetry and literature reference ananku, a concept translated as a "sacred power" that is expressed through and fills women's bodies at menarche, during menstruation, and following childbirth (Jenett 2005, 177). Ananku is considered a precursor to the idea of Shakti ("divine vivifying female power" [Jenett, n.d.]) and the Shakta-Hindu tradition, in which the female body gives "meaning, form, and coherence to religious beliefs, acts, 
and relations" (Patel 1994, 69). In her analysis of Sangam poetry, Dianne Jenett notes parallels between menarchal girls, menstruants, and goddesses. She argues that menstrual taboos and practices "recognize the sacred power of the female and were instituted for reciprocal protection;" they allow a woman to access and use the "sacred power," especially potent during menstruation and after childbirth, to her community's benefit through appropriate self-restraint and separation $(2005,186)$, thus offering an alternate framework for understanding for menstrual restrictions.

The sacred power associated with menstruation is exemplified in the menstruating goddess at the Mahadevar Temple in Chengannur, Kerala. The goddess' menstrual cloth is considered so auspicious and powerful it is auctioned off whenever her menstruation occurs (Jenett 2005, 181; Joseph 2015). Jenett further notes parallels between south Indian menarche rituals and the ritual treatment of the menstruating goddess; these parallels suggest that the menarchal girl is considered to be a goddess (Jenett, n.d.). Contemporary enactment of the Mañcal Nìr A Attu (Turmeric Bathing Ceremony) in Tamil Nadu exemplifies such parallels. While removing ritual impurity, tịttu, is one element of the ceremony, it is not the only dynamic at play. In this ceremony, the menarchal girl is showered in a traditional bath of turmeric and neem-infused water following a period of relative seclusion then dressed in a sari and jewels and presented to kin and neighbors who offer the girl blessings and gifts (Cohen 2017). Once a method for announcing marriageability, the ceremony includes rituals that purify, protect, and strengthen the menarcheal girl at a pivotal moment of transformation and celebrates the "happiness" of menarche (Cohen 2017). ${ }^{4}$ Non-Brahmanical approaches associate an auspiciousness and sacred power with menstruation related to liminality and its generative qualities, which manifests in menarche ceremonies and practices that appear similar to those found in Brahmanical Hinduism but have different motivations.

This section has shown that in both Hinduism and Judaism menstruation is part of larger purity systems, which underlie menstrual restrictions, and that these systems are concerned with the boundaries of identity and community. Both Manu Smriti and the Talmudic discussion of niddah demonstrate a vested interest on the part of their male authors in maintaining their purity, especially regarding the highly communicable modes of sex and touch. While Tractate Niddah is 'about' women and menstruation, it can be read as a text about men's concern with purity, just as Manu Smriti can be read. Though the instructions in Manu Smriti are directed toward (Brahmin) men, ultimately they become institutionalized as behavior modifications women must observe in order to prevent communicating impurity to others. In both instances, menstruation is categorically associated with sex, sexuality, and reproduction and has direct bearing on the status of offspring conceived. Because of the significance such associations carry, the impurity and restrictions framework can end up dominating both practice 
and discourse; however, as this section has also shown alternative framings and interpretations, indigenous to various religious traditions, also exist and deserve the attention of a critical menstrual studies approach to religion and menstruation.

\section{Communicating More Than Impurity}

\section{Communicating Identities and Maintaining Boundaries}

With the menstrual restrictions in Judaism and Hinduism contextualized in their respective systems, this section explores how menstrual practices and traditions, often engaged at the personal or individual level, can become vehicles for defining both individual and communal identities. This discussion deepens inquiry into the relationship between menstruation and religion beyond the personal, subjective, and experiential levels, to which "the paradox approach" may be limited, by engaging larger socio-political contexts and institutional religious dynamics.

In her foundational analysis of Tractate Niddah, Charlotte Elisheva Fonrobert argues that Talmudic discussions of menstruation do more than establish the Laws of Niddah; they contribute to discursive determinations of who belongs to the Jewish community. The rabbinic discourse on body fluids, menstruation, and resulting impurity - which, Fonrobert notes, no longer had bearing on ritual observance at the time of discussion-can be read as demarcating and defining the (Jewish) body politic on a discursive level by defining who should follow the laws and to whom the laws apply (2008, 264). In the period of Late Antiquity in which the Talmudic discussions are set, menstrual blood could signal both gender and Jewish group identity because it was only considered impure if it came from a Jewish woman (Fonrobert 2008, 261). Rabbinic imagination considered non-Jewish menstrual blood and sperm pure (Fonrobert 2008, 263) and thus unable to "communicate" anything. Fonrobert's reading of the Talmudic text shows that, historically, menstruation has been a vehicle for the establishment of group identity and suggests that observance of the Laws of Niddah can be a practical way of signaling group belonging. Contemporary ethnographic studies of women who observe the Laws of Niddah in Israel also demonstrate that adherence to them becomes a site for expressing religious Jewish identity and serves to differentiate the self from a secular other (Avishai 2008, 410). Taking issue with the suggestion that they are impure, some of these women prefer thinking of themselves as 'permissible' or 'forbidden' regarding sexual relations (Avishai 2008, 417), further highlighting the underlying purpose of the laws, in their religiously observant perspective, which is to govern sexual relations and ensure the ritual status of children conceived.

In Hinduism, the contextual background of Brahmanical male purity, understood to be threatened by menstruating women (and women in 
general) as well as 'low' caste individuals, suggests that menstrual restrictions are connected to the larger social inequalities of perpetuated caste-discrimination (see Sukumar [Chapter 13] in this volume). As explained earlier, menstruation is not the only classification that can pollute, and the caste-based classificatory system itself contributes to menstruation's association with impurity. Indeed, gender stratification and caste stratification are co-constituted through the system, and this awareness suggests that perhaps menstrual restrictions serve to preserve caste boundaries. Hindu menstrual restrictions, as presented in a subsection of Dharma literature for women, can be read as intended to make a menstruating woman less attractive and thus less likely to have sex (Hembroff 2010, 59) so as to avoid potentially conceiving a child classified as 'untouchable.' It has been well established that in Brahmanical patriarchy, "women are crucial in maintaining the boundaries between castes" (Chakravarti 2003, 34). Controlling women's sexuality preserves closed boundaries of caste and ensures 'generational purity' in terms of who they copulate with and, I argue, in terms of when they copulate, that is whether they are menstruating or not. For caste creation and control are dependent upon the control of some men and all women for specific (re)productive purposes (Chakravarti 2003, 45).

Analysis of religious menstrual practices at the communal, structural level show the role they play in determining, communicating, and maintaining identities, hierarchies, and culture itself. In both Jewish and Hindu contexts, there is an underlying motive of communicating sexual unavailability during menstruation. Given that in both Hinduism and Judaism intercourse with a menstruant results in a cursed or defiled state of being for a child should one be conceived, this motivation can be read as a patriarchal desire to ensure progeny of a specific identity and thus the assurance of a continued, bounded community. At the same time, since intercourse with a menstruant communicates impurity to a male partner in both contexts, it can be read as a tactic to prevent transmitting impurity through threatening the status of a child should one be conceived. Avishai's work shows how, regardless of how this underlying motivation is interpreted, observance of menstrual laws on an individual level can also communicate something about one's idea to a larger community (religious vs. secular identity). Similarly, the menarche ritual from Tamil Nadu is chiefly concerned with communicating the changed social status of the menarchal girl, who has become a young woman, to the larger community (Cohen 2017). While such rituals follow religious and cultural rules, in this example "Tamil culture is [also] being generated through the performance of a ritual in the form of the girl's coming-of-age [Mañcal Nìr $\overline{A t t u}$ ] ceremony" as well (Sekine 2011, 184).

\section{Menstruation as Catalyst for Religious Change}

The avenues explored thus far help explain the Sabarimala Temple controversy, described at the beginning of the chapter. Initially, outcry centered on the sexism and misogyny perceived to be symbolized within the ban rather than a desire 
to actually enter the Temple (Azad 2015). Following the Supreme Court's 2018 ruling, however, women have attempted to actually enter Sabarimala as devotees (BBC 2019) demonstrating both a symbolic and literal alteration of a centuries-old tradition. But as this chapter's inquiry into Manu Smriti has shown, it is no surprise that "the Sabarimala conflict is also closely bound with India's reckoning with caste" (Nair 2019). In fact, the Supreme Court ruling was passed in the "egalitarian spirit" of the early twentieth-century Temple Entry movement, which sought to secure entrance for individuals from all castes into Hindu temples (Jeffery 1976). The ongoing debate between those who support the traditional Sabarimala ban and those in support of the Supreme Court's ruling, which has been described as pitting "dominant-caste Keralites" against competing interests (Nair 2019), underscores the deeply entwined relationship between menstruation-linked discrimination, gender-based discrimination, and caste-based discrimination. The Sabarimala controversy is a prime example of how pulling on the strings of menstruation and religion results in pulling on the strings of much more than 'impurity' and shows how activism responding specifically to menstruation has the potential to become activism responding to larger issues of systemic discrimination.

Menstruation has been a site for religious institutional transformation in a Jewish context as well. While the Talmudic text primarily locates authority on issues of Niddah with male rabbis, during the late twentieth and early twenty-first centuries, women have claimed Niddah as their own authoritative realm, producing a "niddah cultural industry" (Avishai 2008, 415). This industry includes resources for women with legal questions regarding the Laws of Niddah, marriage, sexuality, and women's health and includes a new leadership role for women within Orthodox communities, the Yoetzet Halacha (Women Halachic Advisor) who guides observance of the Laws of Niddah (Nishmat's Women's Health and Halacha, n.d.). In some liberal Jewish communities, the practice of monthly immersion in the miqvah for married and sexually active unmarried women has been claimed as a valued practice open to personal interpretation with an emphasis on renewal and reflection rather than purification. Miqvaot open to Jews of all denominational backgrounds and all sexual orientations, such as Mayim Hayim and ImmerseNYC, highlight immersion, whether monthly after menstruation or corresponding to any life transition, as a ritual of transformation rather than impurity. Menstruation and its associated practices, rituals, and restrictions have compelled the emergence of new ritual leadership roles for women (Yoetzet Halacha), the reclaiming, reinterpretation, and continuance of rituals (miqvah and menarche rituals), and Supreme Court rulings intended to promote egalitarianism and a spirit of equality. Indeed, these menstruation-focused examples affirm that women's agency can manifest in diverse ways and can motivate the protest against and rejection of menstrual restrictions as well as the reclaiming and adjusting of certain rituals-both of which ultimately have bearing on religious traditions and cultures, themselves, overall. 


\section{Conclusion}

There is a rich relationship between menstruation and religion offering many avenues for inquiry. Religiously motivated menstrual observances have become a primary site through which this relationship is explored. The ways in which those practices are claimed as an inherent part of one's religion, rejected as too restricting and/or misogynistic, or re-claimed with alterations make them worthy of further study. Research into menstruation and religion should certainly include the following considerations: what codified and/or inherited explanations are provided for religious menstrual practices? Do women develop their own explanations? What are the larger contexts for understanding menstruation and menstrual practices in this religion? How do individuals engage with and feel about menstrual laws and practices? How have menstrual practices and observances changed over time?

But as this chapter demonstrates, a critical menstruation studies approach to menstruation and religion is situated in other axes of engagement as well. Through engaging menstruation as a theoretical concept and physiological reality in the broad contexts of Judaism and Hinduism, this chapter has contextualized menstrual practices within larger religious purity systems, exploring the complex intersection of menstruation and religion beyond a framework of restrictions. This chapter has approached menstrual practices through an inquiry into what and how they contribute to better understanding the ways a religious community defines and (re)produces itself. As such, it shifts away from the question of merely wondering how religious women may meaningfully navigate compliance with menstrual practices. It has demonstrated that menstruation can be read as a site through which women's sexuality - and by extension the boundaries of the religious community and maintenance of social hierarchies-are controlled according to particular ideologies, producing the idea that women are bearers of tradition and responsible for the wellbeing of the family, society, and religion itself. At the same time, menstruation and menstrual practices can become vehicles for change and innovation within religious contexts. The communal and institutional elements of menstruation within religion are important to include in menstruation and religion discourse, especially those concerned with policy issues and behavior modifications, for they highlight the larger referential systems that are so essential to any type of change involving menstruation within the context of religion.

\section{Notes}

1. For a detailed account see "An Abbreviated History of the Development of the Jewish Menstrual Laws," by Tirzah Meacham in Women and Water: Menstruation in Jewish Life and Law, edited by Rachel Wasserfall (1999). For analysis of how theories of menstruation have changed over time within Judaism see Steinberg (1997). 
2. Ayurveda offers an additional framework through which menstruation and menstrual restrictions can be understood, although there is not space here for discussion. Traditional Ayruvedic texts do not associate menstruation with pollution or negativity and instead discuss menstruation in the context of conception, noting that the days of menstruation are not conducive to conception (Leslie 1994, 69). For an Ayruvedic contextualization of menstruation see Hembroff (2010), Joseph (2015), Leslie (1994).

3. There are diverse interpretations of and ways of relating to this Vedic story; see Flueckiger $(2013,103)$ for an account of how women in Andhra Pradesh understand it positively, explaining it suggests women's unparalleled generosity, strength, and power.

4. For more on the relationship between menarche rituals and divinity see Judy Grahn's metaformic theory (1993); for further analysis of this menarche ceremony and its variations see Kapadia (1995), Bhattacharyya (1975), Ram (1996).

\section{REFERENCES}

Apffel-Marglin, Frédérique. 2008. Rhythms of Life: Enacting the World with the Goddesses of Orissa. Oxford Collected Essays. Oxford, New York: Oxford University Press.

Avishai, Orit. 2008. "'Doing Religion in a Secular World': Women in Conservative Religions and the Question of Agency." Gender and Society 22 (4): 409-33. https://doi.org/10.1177/0891243208321019.

Azad, Nikita. 2015. "\#HappyToBleed: An Initiative Against Sexism." Countercurrents. org., November 23, 2015. http://www.countercurrents.org/azad231115.htm.

Bhartiya, Aru. 2013. "Menstruation, Religion and Society." International Journal of Social Science and Humanity 3 (6): 523-27. https://doi.org/10.7763/ijssh.2013. v3.296.

Bhattacharyya, N. N. 1975. Ancient Indian Rituals and Their Social Contents. London: Curzon Press.

Boyarin, Daniel. 1993. Carnal Israel: Reading Sex in Talmudic Culture. Berkley, CA: University of California Press.

Chakravarti, Uma. 2003. Gendering Caste through a Feminist Lens. Calcutta, India: STREE.

Cohen, Ilana. 2017. More Than Blood: Menarche Ceremonies and Menstrual Hygiene in Tamil Nadu, India. Unpublished Manuscript.

Collins, John. 2004. Introduction to the Hebrew Bible, 145-47. Canada: Fortress Press.

Dunnavant, Nicki, and Tomi-Ann Roberts. 2012. "Restriction and Renewal, Pollution and Power, Constraint and Community: The Paradoxes of Religions Women's Experiences of Menstruation." Sex Roles. https://doi.org/10.1007/ s11199-012-0132-8.

Eilberg-Schwartz, Howard. 1990. The Savage in Judaism: An Anthropology of Israelite Religion and Ancient Judaism. Bloomington: Indiana University Press.

Fonrobert, Charlotte Elisheva. 2008. "Blood and Law: Uterine Fluids and Rabbinic Maps of Identity. Henoch 30 (2): 243-66.

Flueckiger, Joyce. 2013. "Female-Narrated Possibilities of Relationship." In When the World Becomes Female: Guises of a South Indian Goddess, 97-112. Indiana: Indiana University Press. 
Grahn, Judy. 1993. Blood, Bread and Roses: How Menstruation Created the World. Boston: Beacon Press.

Hauptman, Judith. 1998. "Rereading the Rabbis: A Woman's Voice.” Boulder, CO: Westview Press.

Hembroff, Nicole. 2010. "Orthodox Hindu Attitudes to Menstruation." MA Thesis, University of Lethbridge. https://www.uleth.ca/dspace/bitstream/handle $/ 10133 / 2600 /$ hembroff $\% 2 \mathrm{C} \% 20$ nicole.pdf? sequence $=1$ \&isAllowed $=y$.

Jeffery, Robin. 1976. "Temple-Entry Movement in Travancore, 1860-1940." Social Scientist 4 (8): 3-27.

Jenett, Dianne E. 2005. "Menstruating Women/Menstruating Goddess: Sites of Sacred Power in South India." In Menstruation: A Cultural History, edited by Andrew Shail and Gillian Howie. New York, NY: Palgrave Macmillan.

—. n.d. "Menstruating Women/Menstruating Goddesses: Sites of Sacred Power in Kerala, South India, Sangam Era (100-500 CE) to the Present.” Metaformia. http:// www.metaformia.org/articles/menstruating-women-menstruating-goddesses/.

Joseph, Sinu. 2015. "Unearthing Menstrual Wisdom-Why We Don't Go to the Temple, and Other Practices." Mythri: Imparting Awareness on Menstrual Hygiene to Adolescent Girls. https://mythrispeaks.wordpress.com/2015/05/28/ unearthing-menstrual-wisdom-why-we-dont-go-to-the-temple/.

Kapadia, Karin. 1995. Siva and Her Sisters: Gender, Caste, and Class in Rural South India. Boulder, CO: Westview Press.

Leslie, Julia. 1989. The Perfect Wife: The Orthodox Hindu Woman According to the Stridharmapaddhati of Tryambakayajvan. Delhi, India: Oxford University Press.

-. 1994. "Some Traditional Indian Views on Menstruation and Female Sexuality." In Sexual Knowledge, Sexual Science, edited by Roy Porter and Mikulas Teich, 63-81. Cambridge, Great Britain: Cambridge University Press.

Meacham (leBeit Yoreh), Tirzah. 1999. "An Abbreviated History of the Development of the Jewish Menstrual Laws." In Women and Water: Menstruation in Jewish Life and Law, edited by Rachel Wasserfall, 23-39. Hanover: Brandeis University Press.

- 2009. "Female Purity (Niddah)." Jewish Women: A Comprehensive Historical Encyclopedia, March 1, 2009. Jewish Women's Archive. https://jwa.org/ encyclopedia/article/female-purity-niddah.

Nair, Supriya. 2019. "Two Women Enter a Temple. A Country Erupts." The New York Times, January 8, 2019. https://www.nytimes.com/2019/01/08/opinion/ india-women-sabarimala-temple.html.

Nishmat's Women's Health and Halacha. n.d. "Yoatzot Halacha." Accessed October 16, 2018. http://www.yoatzot.org/about-us/default.asp?id=593.

Olivelle, Patrick. 2004. Manu's Code of Law: A Critical Edition and Translation of the Manava-Dharmasastra. New York, NY: Oxford University Press.

Patel, Kartikeya C. 1994. "Women, Earth, and the Goddess: A Shākta-Hindu Interpretation of Embodied Religion." Hypatia 9 (4): 69-87.

Ram, Kalpana. 1996. "Uneven Modernities and Ambivalent Sexualities: Women's Constructions of Puberty in Coastal Kanyakumari, Tamil Nadu." In Handbook of Gender, edited by Raka Ray. New Delhi: Oxford University press.

"Sabarimala Temple: Indian Women Form ' $620 \mathrm{~km}$ Human Chain' for Equality." BBC News online. Last modified January 1, 2019. https://www.bbc.com/news/ world-asia-india-46728521. 
Sacred Texts. n.d. "Chapter V. The Laws of Manu." Accessed October 16, 2018. http://www.sacred-texts.com/hin/manu/manu05.htm.

Sekine, Yasumasa. 2011. Pollution, Untouchability, and Harijans: A South Indian Ethnography. New Delhi: Rawat Publications.

Sharma, Nitika. 2014. "From Fixity to Fluidity: Menstrual Ritual Change among Hindu Women of Nepalese Origin." PhD diss., University of Colorado Boulder. https:// scholar.colorado.edu/cgi/viewcontent.cgi?article=1002\&context=socy_gradetds.

Steinberg, Jonah. 1997. "From a 'Pot of Filth' to a 'Hedge of Roses' (And Back): Changing Theorization of Menstruation in Judaism." Journal of Feminist Studies in Religion 13 (2): 5-26.

The Laws of Manu. 1991. Translated by Wendy Doniger. London, England: Penguin Books.

The Veda of the Black Yajus School entitled Taittiriya Sanhita. 1914. Translated by Arthur Berriedale Keith. Cambridge, MA. http://www.sanskritweb.net/ yajurveda/keith.pdf.

Whitekettle, Richard. 1996. "Levitical Thought and the Female Reproductive Cycle: Wombs, Wellsprings, and the Primeval World." Vetus Testamentum 46 (3): 376-91.

"Why Are Indian Women 'Happy to Bleed'?" BBC News online. Last modified November 23, 2015. http://www.bbc.com/news/world-asia-india-34900825.

Open Access This chapter is licensed under the terms of the Creative Commons Attribution 4.0 International License (http://creativecommons.org/licenses/ by/4.0/), which permits use, sharing, adaptation, distribution and reproduction in any medium or format, as long as you give appropriate credit to the original author(s) and the source, provide a link to the Creative Commons license and indicate if changes were made.

The images or other third party material in this chapter are included in the chapter's Creative Commons license, unless indicated otherwise in a credit line to the material. If material is not included in the chapter's Creative Commons license and your intended use is not permitted by statutory regulation or exceeds the permitted use, you will need to obtain permission directly from the copyright holder.

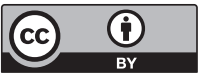

